\title{
Prone Positioning in Awake and Asleep Patients with COVID-19
}

\author{
Sriharsha Tatineni, Vishal Shanbhag ${ }^{1}$ \\ Department of Respiratory Therapy, Al Rahba Hospital, Abu Dhabi, UAE, 'Department of Critical Care, Kasturba Medical College, Manipal, Karnataka, India
}

\section{Abstract}

Prone positioning has been found to be beneficial in both awake (self-proning) and mechanically ventilated population with acute respiratory distress syndrome due to severe COVID-19. Since the process has the potential to avoid possible intubation in a certain group of patients, prone positioning should be considered early on during COVID-19 treatment. With stepwise and careful approach involving a dedicated team of clinicians and with the help of adequate monitoring, benefits of the process can be achieved. It can contribute to offloading of resources and manpower burden in the pandemic if applied timely in the recommended group of patients.

Keywords: COVID-19, prone positioning, prone ventilation, SARS-CoV, self-proning

\section{INTRODUCTION}

SARS CoV 2 or severe acute respiratory syndrome coronavirus-2 was documented to have originated in Wuhan, China, and quickly spread to the rest of the world causing till date widespread loss of lives. The causative organism was identified as a strain similar to the SARS coronavirus or SARS-CoV. The disease has been since named coronavirus disease 19 or COVID-19. Meanwhile, documented clinical experience of the clinicians helps their peers to find possible treatment strategies to give their patients the best chance of survival. ${ }^{[1]}$

The disease is known to affect multiple organs but primarily the respiratory system. The manifestation of the respiratory symptoms includes dyspnea, fever, and dry cough. ${ }^{[2]}$ In addition to these symptoms, headache, dizziness, generalized weakness, vomiting, and diarrhea are observed..$^{[3]}$

The radiological evidence of the patients was characterized by more than half of the patients presenting with bilateral, multifocal lesions, with peripheral distribution. Ground-glass opacities, consolidation, crazy paving pattern, interlobular thickening, and adjacent pleura thickening have been observed. ${ }^{[4]}$ Acute respiratory distress syndrome is the most common indication for transferring patients with COVID-19 to the intensive care unit (ICU) and the major cause of death in this patient population. Imaging patterns corresponding to clinical improvement usually occur after week 2 of the disease

\begin{tabular}{|l|l|}
\hline \multicolumn{3}{|c|}{ Access this article online } \\
\hline Quick Response Code: & Website: \\
\hline & www.ijrc.in \\
\hline
\end{tabular}

and include gradual resolution of consolidative opacities and decrease in the number of lesions and involved lobes. ${ }^{[4]}$

\section{Prone Position and Acute Respiratory Distress SYNDROME}

Prone positioning is used extensively to improve oxygenation in severe hypoxemic respiratory failure.

Several studies including the PROSEVA trial have shown that prone positioning helps improve functional residual capacity by shifting the diaphragm and abdominal contents away from the lung, improve V/Q mismatch, improve drainage of secretions and water away from dorsal lung regions, and develop higher transpulmonary pressure in dorsal lung regions, thus improving ventilation. ${ }^{[5-7]}$

Awake early self-proning in an emergency department in New York City demonstrated improved oxygen saturation in COVID-19 positive patients. They measured the change in oxygen saturation 5 min after self-proning in 50 patients with hypoxia and suspected (subsequently confirmed) COVID-19.

Address for correspondence: Dr. Vishal Shanbag, Associate Professor, Department of Critical Care Kasturba Medical College Manipal Academy of Higher Education, Manipal, Karnataka, India. E-mail: docvishalshan@gmail.com

This is an open access journal, and articles are distributed under the terms of the Creative Commons Attribution-NonCommercial-ShareAlike 4.0 License, which allows others to remix, tweak, and build upon the work non-commercially, as long as appropriate credit is given and the new creations are licensed under the identical terms.

For reprints contact: WKHLRPMedknow_reprints@wolterskluwer.com

How to cite this article: Tatineni S, Shanbhag V. Prone positioning in awake and asleep patients with COVID-19. Indian J Respir Care 2021;10:S29-33.

Received: $23-01-2021$

Accepted: 04-03-2021
Revised: 04-03-2021 Published: 29-04-2021 
Patients with moderate to severe hypoxemia related to COVID-19 demonstrated improvement in $\mathrm{SpO}_{2}$ after placing prone. ${ }^{[8]}$

In a small single-center cohort study by Thompson et al., it was found that prone position in spontaneously breathing awake patients with severe hypoxia was associated with improved oxygenation and avoided intubation in a certain group of patients. ${ }^{[9]}$

Available evidence suggests that prone positioning must be considered early in the disease process of acute respiratory distress syndrome and provides absolute survival advantage of $10 \%-17 \%$.

\section{Indications and Contraindications}

The protocol followed in our facility includes the selection of patients based on the criteria for prone ventilation and excluding patients with any documented contraindications.

Prone position is an option for intubated and mechanically ventilated patients with $\mathrm{L}$ type with good compliance of $>40 \mathrm{ml} / \mathrm{cm} \mathrm{H}_{2} \mathrm{O}$ but who are hypoxic. It may also be considered in intubated and mechanically ventilated patients with severe acute respiratory distress syndrome $\left(\mathrm{PaO}_{2} / \mathrm{FiO}_{2}<150\right.$ with $\left.\mathrm{FiO}_{2} \geq 0.9, \mathrm{PEEP} \geq 15 \mathrm{~cm} \mathrm{H}_{2} \mathrm{O}, \mathrm{V}_{\mathrm{T}}=6 \mathrm{~mL} / \mathrm{kg} \mathrm{PBW}\right) \mathrm{H}$ type of lung and that has failed recruitment methods. It can be considered as an alternative to Bilevel/APRV (RESCUE THERAPY). Prone positioning is done within $6 \mathrm{~h}$ of establishing that the patient meets the above criteria. The prone position is maintained for $16-20 \mathrm{~h}$ at one stretch.

Absolute contraindications to prone positioning include hemodynamic instability with increasing vasopressor requirement, severe intracranial hypertension, recent surgeries that hinder positioning prone (facial surgery, tracheal surgery, sternotomy, ophthalmic surgery, and abdominal surgery), skeletal fractures, abdominal compartment syndrome, second/third trimester of pregnancy, and patients that have previously shown poor tolerance of prone positioning. Other contraindications include massive hemoptysis, alveolar hemorrhage, major hemorrhage, major burns, new tracheostomy, seizures, and extreme obesity body mass index $>40 \mathrm{~kg} / \mathrm{m}^{2} .{ }^{[8]}$

\section{Preparation}

Extensive preparation precedes the process of prone positioning. A team is commissioned that includes ICU physician/anesthetists, respiratory therapist, physiotherapist, anesthesia technicians, and ICU nurses. The team members wear full PPE and ensure safety with help of buddy check and leak test.

The ICU physician and/or anesthetist, respiratory therapist, and/or the anesthesia technician comprise the "airway team."

The process of prone positioning in a mechanically ventilated patient is performed using the "sandwich technique." The process is carried with closed-loop communication with the physician under their direction. The process is reviewed amongst the team members before actually performing the technique. The steps of turning a mechanically ventilated patient from supine to prone position are as follows [Figures 1-6].

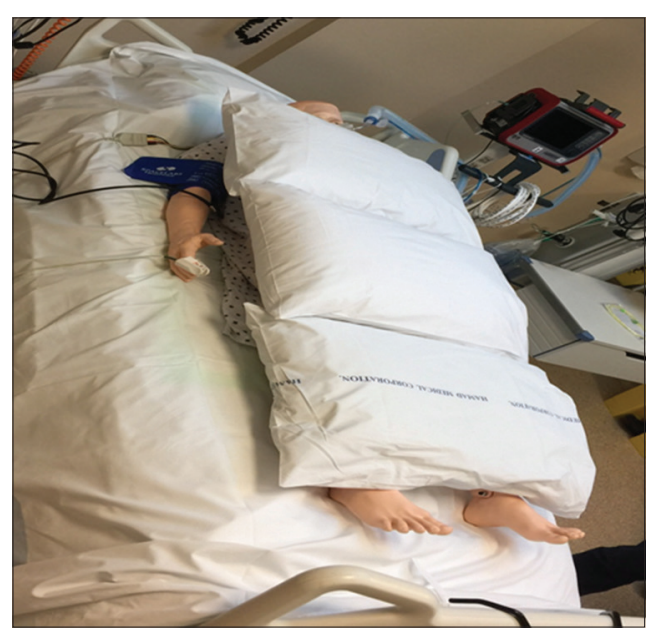

Figure 1: Pillows placed over the chest, pelvis, and shin

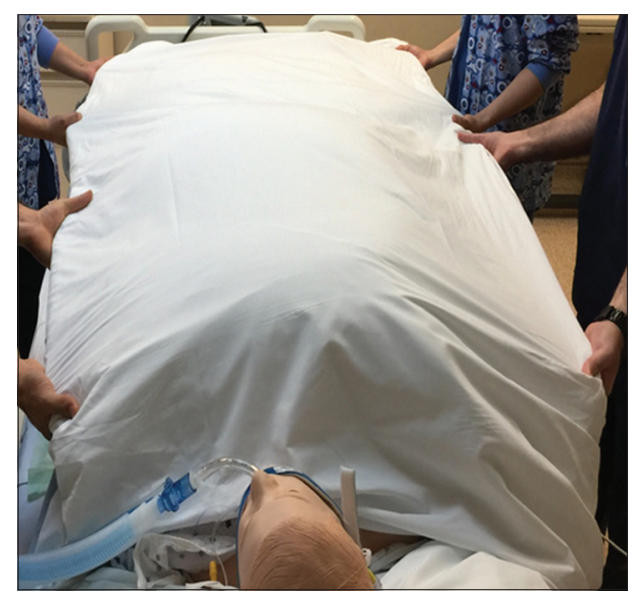

Figure 2: The patient's body and pillows covered with a sheet

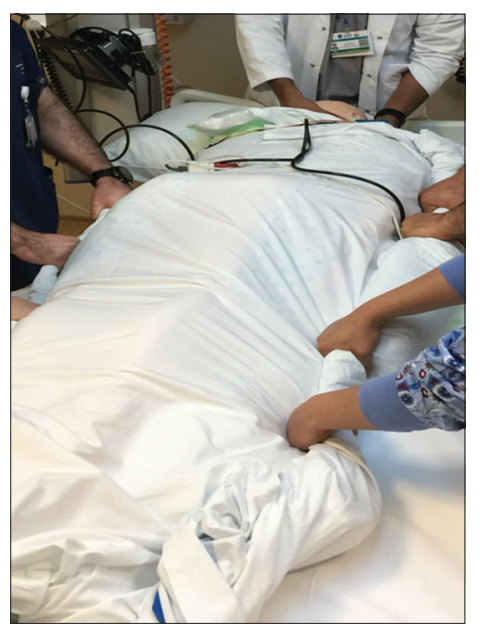

Figure 3: The "cornish pastry" (refer text for details) 
Tatineni and Shanbhag: Prone positioning as a treatment strategy in COVID-19 patients

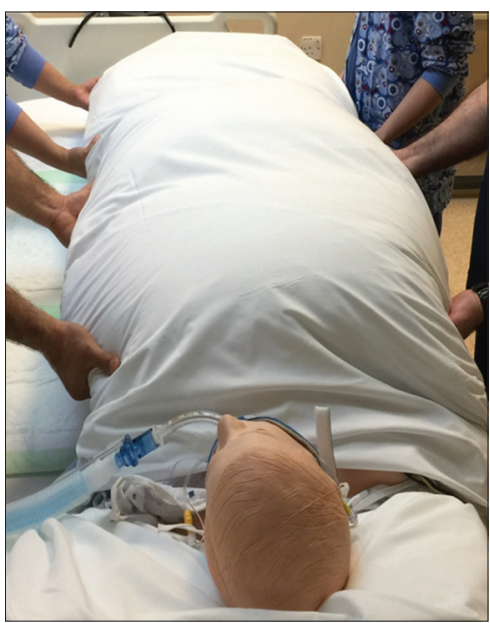

Figure 4: Patient pulled toward the edge of the bed, away from the intended direction of turn

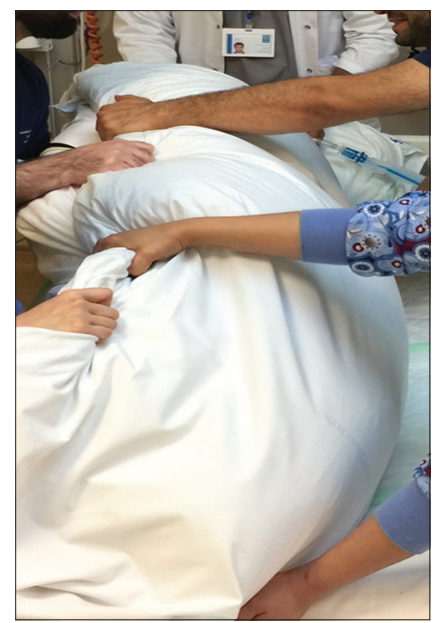

Figure 5: Patient placed in the lateral position, maintaining sheet integrity

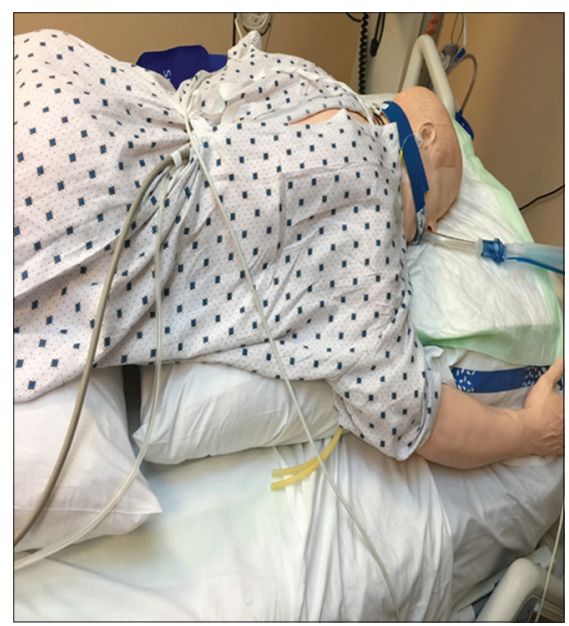

Figure 6: Patient turned prone, top sheet removed, and face turned to one side and supported

1. The bed and bottom sheet should be pulled straight and taut. Place the patient's arms along the sides and tuck the hands of the patient under the torso
2. Pillows are placed over the chest, pelvis, and shin

3. A sheet is placed covering the patient's body and pillows excluding the head

4. Roll the long edges of the top and bottom sheets tightly together close to the patient's body to cocoon the patient firmly in between them.("The Cornish Pastry")

5. Pull the patient toward the edge of the bed, away from the intended direction of turn

6. Slowly position the patient in lateral decubitus position, maintaining sheet integrity

7. Recheck airway, vital signs, ventilator tubing, ventilator readings, lines, tubes, and drains

8. Turn the patient slowly completely prone onto the original top sheet

9. Place the head onto the face cradle. If a face cradle is not used, the head must be turned to one side and supported

10. The ICU physician and respiratory therapist should auscultate the chest to ensure bilateral equal air entry and the respiratory therapist should assess cuff pressure and endotracheal tube for any kinks or disruption in ventilation.

The process includes continuous monitoring of the patient. Transient hypoxia is common immediately after prone positioning and it improves within a few minutes. Swimmer's position is maintained. The head is repositioned by turning sides every $4 \mathrm{~h}$ (optional). If a face cradle is used, check for redness or pressure injuries. Overextension and compression of joints should be avoided by proper positioning. Deep sedation is maintained (Richmond Agitation Sedation Scale - 4). Paralysis is done if indicated. If hemodynamically permissible, anti-Trendelenburg position $\left(15^{\circ}-30^{\circ}\right)$ may be given.

Complications that may arise during the process may include worsening of oxygenation, dislodgement of the airway, vascular accesses, and tubes. Development of pressure sores in the periorbital area and face, cheeks, chin, knees, toes, breasts, and genitalia is not uncommon. Nerve injury including brachial plexus injury, ulnar and peroneal nerve injuries, and cardiac arrest are also potential complications of prone positioning.

Hemodynamic instability and worsening of oxygenation that does not improve within 15-30 min of prone positioning, $\mathrm{SpO}_{2}<85 \%$, and cardiac arrest are indications to discontinue the procedure immediately. Nonresponders include patients whose blood gas analysis shows the reduction in oxygenation and retention of carbon dioxide by $20 \%$ compared to baseline blood gas results. Criteria that indicate the success of prone positioning are increase in $\mathrm{PaO}_{2} / \mathrm{FiO}_{2}$ by 20 (or by $>5 \%$ ) or increase in $\mathrm{PaO}_{2}$ by $>10 \mathrm{mmHg}$. Prone positioning is discontinued once the goal of increasing $\mathrm{PaO}_{2} / \mathrm{FiO}_{2}>150$ with $\mathrm{FiO}_{2} \leq 0.6$ and requirement of PEEP $\leq 10 \mathrm{~cm} \mathrm{H} \mathrm{H}_{2} \mathrm{O}$ are achieved.

Understanding the correct pathophysiology is crucial to establishing the basis for appropriate treatment. ${ }^{[10]}$ 


\begin{tabular}{|c|c|}
\hline Team member, position & Role \\
\hline ICU physician/anesthetists, head end & Team lead coordinating the maneuver \\
\hline Respiratory therapist, next to ventilator & $\begin{array}{l}\text { Preoxygenation, secures ETT, avoids disconnection, airway management in emergency, face cradle } \\
\text { placement, fourth hourly checks to avoid pressure sores on the face }\end{array}$ \\
\hline $\begin{array}{l}\text { Physiotherapists and practical nurses, } \\
\text { distributed on either side of the patient }\end{array}$ & Turning the patient in coordination as per the physician's prompt \\
\hline Primary/registered nurse & Ensures securing of all the lines and tubes \\
\hline
\end{tabular}

ETT: Endotracheal tube, ICU: Intensive care unit

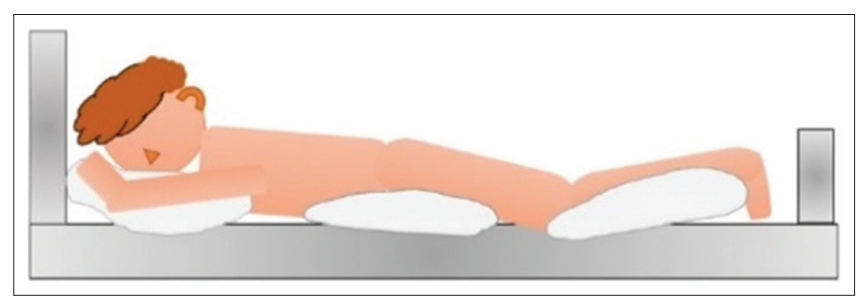

Figure 7: 30 min to $2 \mathrm{~h}$ lying prone on the belly

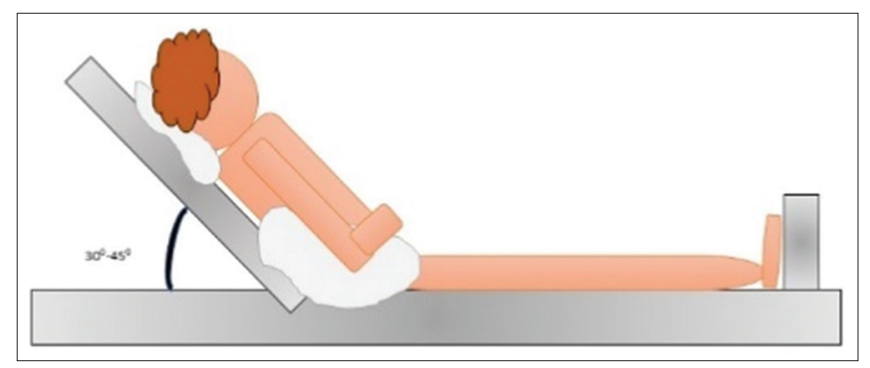

Figure 9: 30 min to $2 \mathrm{~h}$ semi-fowler's position

\section{Prone Position in Awake Patients}

Given the improvement in mechanically ventilated patients, it has been postulated that adopting the prone position for conscious COVID-19 patients may benefit them in terms of improving oxygenation, reducing the need for invasive ventilation, and potentially even reducing mortality. Patients who are able to communicate and are independently able to rotate to the front and adjust the position with no anticipated airway issues qualify for awake prone positioning. ${ }^{[1]}$

Evidence in awake prone positioning is limited to case series and small observational studies with heterogenous approaches to noninvasive respiratory support. These reports demonstrated short-term improvements in oxygenation $\left(\mathrm{PaO}_{2}\right)$ and reduced $\mathrm{FiO}_{2}$ requirements with no harm to patients. ${ }^{[12-14]}$

The responsibility of various team members during prone positioning is listed in Table 1. The steps for the awake prone position are shown in Figures 7-10.

Awake prone positioning can be a low-risk, low-cost maneuver that can help delay or reduce the need for intensive care in patients with COVID-19 pneumonia. This in itself is a significant factor, considering that the number of critically ill patients with COVID-19 pneumonia is expected to increase. ${ }^{[15]}$

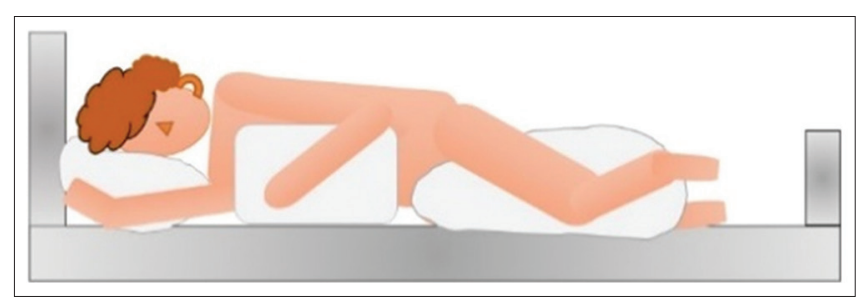

Figure 8: 30 min to $2 \mathrm{~h}$ lying on the right side

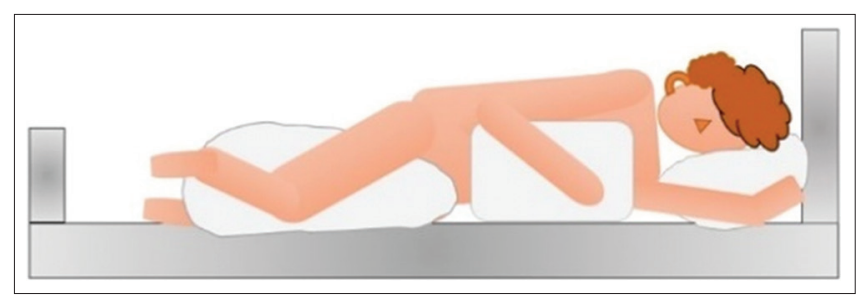

Figure 10: 30 min to $2 \mathrm{~h}$ lying on his left side

\section{ConcLusion}

Prone positioning has shown the ability to improve oxygenation in intubated as well as awake COVID-19 patients. Spontaneously breathing patients with COVID-19 also report subjective improvement and may have the potential to help avoid intubation. However, further studies with larger sample size on injuries associated with prone positioning in asleep and awake patients are required.

\section{Financial support and sponsorship}

Nil.

\section{Conflicts of interest}

There are no conflicts of interest.

\section{ReFEREnCES}

1. Yuki K, Fujiogi M, Koutsogiannaki S. COVID-19 pathophysiology: A review. Clin Immunol 2020;215:108427.

2. Huang C, Wang Y, Li X, Ren L, Zhao J, Hu Y, et al. Clinical features of patients infected with 2019 novel coronavirus in Wuhan, China. Lancet 2020;395:497-506.

3. Shi $\mathrm{H}$, Han X, Jiang N, Cao Y, Alwalid O, Gu J, et al. Radiological findings from 81 patients with COVID-19 pneumonia in Wuhan, China: A descriptive study. Lancet Infect Dis 2020;20:425-34.

4. Xu X, Yu C, Qu J, Zhang L, Jiang S, Huang D, et al. Imaging and clinical features of patients with 2019 novel coronavirus SARS-CoV-2. Eur J Nucl Med Mol Imaging 2020;47:1275-80.

5. Guérin C, Reignier J, Richard JC, Beuret P, Gacouin A, Boulain T, et al. Prone positioning in severe acute respiratory distress syndrome. N Engl 
J Med 2013;368:2159-68.

6. Gattinoni L, Taccone P, Carlesso E, Marini JJ. Prone position in acute respiratory distress syndrome. Rationale, indications, and limits. Am J Respir Crit Care Med 2013;188:1286-93.

7. Messerole E, Peine P, Wittkopp S, Marini JJ, Albert RK. The pragmatics of prone positioning. Am J Respir Crit Care Med 2002;165:1359-63.

8. Caputo ND, Strayer RJ, Levitan R. Early Self-Proning in Awake, Non-intubated Patients in the Emergency Department: A Single ED's Experience During the COVID-19 Pandemic. Acad Emerg Med 2020;27:375-8.

9. Thompson AE, Ranard BL, Wei Y, Jelic S. Prone Positioning in Awake, Nonintubated Patients With COVID-19 Hypoxemic Respiratory Failure. JAMA Intern Med 2020;180:1537-9.

10. Gattinoni L, Chiumello D, Caironi P, Busana M, Romitti F, Brazzi L, et al. COVID-19 pneumonia: Different respiratory treatments for different phenotypes? Intensive Care Med 2020;46:1099-102.

11. Bamford P, Bentley A, Dean J, Whitmore D and Wilson-Baig N,
ICS Guidance for Prone Positioning of the Conscious COVID Patient 2020. Available from: https:/emcrit. org/wp-content/ uploads/2020/04/2020-04-12-Guidance-for-conscious-proning. pdf. [Last accessed 2021 Jan 20].

12. Valter C, Christensen AM, Tollund C, Schønemann NK. Response to the prone position in spontaneously breathing patients with hypoxemic respiratory failure. Acta Anaesthesiol Scand 2003;47:416-8.

13. Scaravilli V, Grasselli G, Castagna L, Zanella A, Isgrò S, Lucchini A, et al. Prone positioning improves oxygenation in spontaneously breathing nonintubated patients with hypoxemic acute respiratory failure: A retrospective study. J Crit Care 2015;30:1390-4.

14. Ding L, Wang L, Ma W, He H. Efficacy and safety of early prone positioning combined with HFNC or NIV in moderate to severe ARDS: A multi-center prospective cohort study. Crit Care 2020;24:28.

15. Ng Z, Tay WC, Ho CHB. Awake prone positioning for non-intubated oxygen dependent COVID-19 pneumonia patients. Eur Respir J 2020;56:2001198. 